\title{
DISTRIBUIÇÃO DA CONCENTRAÇÃO DE PM10 DURANTE UM EVENTO DE INVERSÃO TÉRMICA EM VITÓRIA-ES UTILIZANDO O MODELO CMAQ
}

\author{
Alexandre S. Magalhães, Elson S. Galvão e Rita C. Feroni e Taciana T. A. Albuquerque \\ Departamento de Engenharia Ambiental - UFES \\ ams_prof@yahoo.com.br
}

\section{RESUMO}

O estudo teve como objetivo simular os níveis de concentração de material particulado inalável (PM10), utilizando o modelo CMAQ durante um evento de inversão térmica ocorrido em Vitória-ES no dia 25 de julho de 2013. Os resultados mostraram um aumento nas concentrações de PM10 no período do evento, sendo dispersa após a quebra da inversão.

\begin{abstract}
The study aimed to simulate the concentration levels of inhalable particulate matter (PM10) using the CMAQ model for a thermal inversion event occurred in Vitória-ES on July 25, 2013. The outcome showed an increase in the concentration of PM10 during the event, being dispersed after the inversion break.
\end{abstract}

\section{INTRODUÇÃO}

Inversões térmicas proporcionam condições estáveis da atmosfera, inibindo os fluxos verticais, concentrando os poluentes abaixo desta camada. Este fenômeno é causado pelo repouso de uma parcela de ar quente sobre uma parcela de ar frio adjacente ao solo (OKE, 1987). Estudos têm caracterizado o perfil vertical da CLP (GALVÃO et al., 2013) durante episódios de inversão térmica, com o objetivo de avaliar a capacidade dispersiva da atmosfera (WALLACE e KANAROGLOU, 2009). 


\section{METODOLOGIA}

A simulação dos níveis de concentração de PM10, utilizando o Community Multiscale Air Quality Model (CMAQv4.6) (BYUN et al., 1999) foi inicializada 24 horas antes do evento de inversão térmica, o qual ocorreu no dia 25 de julho de 2013. Como dado de entrada para o CMAQ, utilizou-se a saída do modelo meteorológico WRFv3.2.1 (Weather Research and Forecasting), inicializado com dados do GFS com resolução de $1^{\circ}$ e o modelo de emissão SMOKEv2.4(Sparse Matrix Operator Kernel Emissions), o qual foi inicializado com os dados do inventário de fontes, fornecido pelo Instituto Estadual de Meio Ambiente e Recursos Hídricos do Espírito Santo (IEMA), com base nos anos de 2009/2010. Os cenários de qualidade do ar foram gerados com uma resolução espacial de $1 \mathrm{~km}$, abrangendo uma área de 60 por 80 km, a qual corresponde a Região da Grande Vitória (RGV).

\section{RESULTADOS E DISCUSSÃO}

Conforme Figura 1, uma inversão térmica ocorreu entre 6 e 9h da manhã, causando o aprisionamento de poluentes em uma fina camada variando entre 70 e $100 \mathrm{~m}$ de altura.

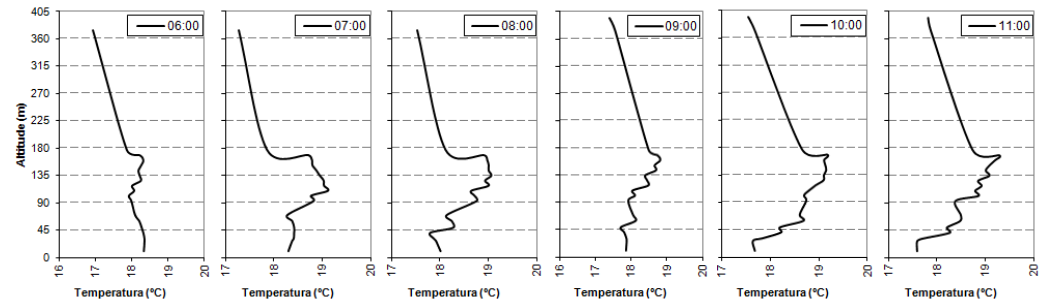

Figura 1: Perfis verticais de temperatura simulados pelo WRF entre 06:00 e 11:00 horas. Fonte. Feroni et al. (2013).

As Figuras 2 e 3 apresentam as concentrações de PM10 para os primeiros 15 níveis simulados, correspondendo a uma altura aproximada de $150 \mathrm{~m}$, altura superior à altura de inversão. Neste período, o modelo CMAQ previu o aprisionamento de poluentes e, consequentemente, o aumento nas concentrações de PM10, apresentando às $7 \mathrm{~h}$ concentrações aproximadas de $127 \mu \mathrm{g} \mathrm{m}^{-3}$ e $80 \mu \mathrm{g} \mathrm{m}^{-3}$ entre alturas de 17 e $60 \mathrm{~m}$, respectivamente (Figura 2). De acordo com a Figura 3, é evidente que acima da camada de inversão térmica (Figura 1) os efeitos da poluição são bem menos expressivos, apresentando 
concentrações de particulados na ordem de $30 \mu \mathrm{g} \mathrm{m} \mathrm{m}^{-3}$, valor semelhante às concentrações de background.

A partir das 10 h, observa-se uma diminuição nas concentrações de PM10 em todos os níveis simulados, coincidindo com o fim da inversão térmica, o que ocasionou o aumento da altura da camada de mistura, diluindo os poluentes dentro desta. Os picos de concentração observados entre 16 e $19 \mathrm{~h}$ podem ser relacionados ao aumento de tráfego veicular, típico do horário, associado à diminuição do fluxo convectivo e o início da estabilidade da atmosfera com o inicio da formação da camada limite noturna.

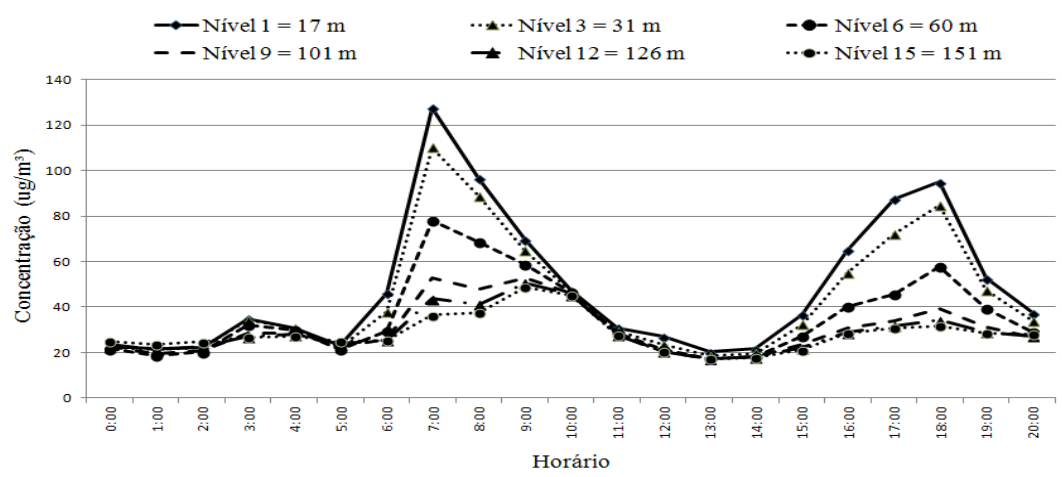

Figura 2. Evolução horária das concentrações de PM10 em níveis verticais na atmosfera da RGV para o dia 25 de julho de 2013.

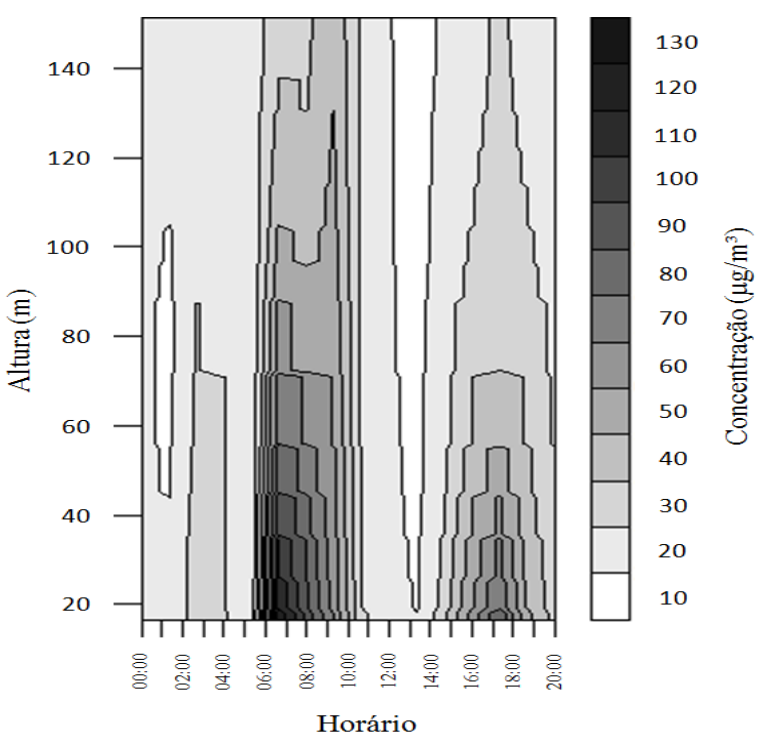

Figura 3. Concentração vertical e temporal de PM10. 


\section{CONCLUSÕES}

Conclui-se a partir dos resultados que o modelo CMAQ conseguiu simular a variação vertical e temporal da concentração de PM10 durante o evento, demonstrando ser uma importante ferramenta na previsão de episódios de poluição atmosférica e tomada de decisões e medidas de controle ambiental.

\section{AGRADECIMENTOS}

Á CAPES e CNPQ, pelo apoio financeiro.

\section{REFERÊNCIA}

BYUN, D. W. e CHING, J. K. S, (EDs). Science algorithms of the EPA Models-3 Community Multiscale Air Quality Modeling System. EPA-600/R-99/030. Office of Research and Development, U.S. Environmental Protection Agency, Washington, D.C. 1999.

FERONI, R. C. et al. Análise de diferentes parametrizações físicas do wrf para um caso de inversão térmica em vitória-es. Submetido à revista: Ciência e Natura. 2013.

GALVÃO, E. S. et al. Altura da CLC no horário de 12 UTC para a região de Vitória-ES entre 2008 e 2012. Submetido à revista: Ciência e Natura. 2013.

IEMA. Relatório da Qualidade do ar na Região da Grande Vitória, 2008.

OKE, T.R. Boundary Layer Climates, 2ª ed. Routledge, 1987.

SKAMAROCK, W.C., KLEMP, J.B. A time-split non-hydrostatic atmospheric model. Journal of Computational Physics, n. 227, p. 3465-3485, 2008.

WALLACE, J.; NAIR, P.; KANAROGLOU, P. Atmospheric remote sensing to detect effects of temperature inversions on sputum cell counts in airway diseases. Environmental Research, v. 110, n. 6, p. 624-632, 2010. 